\title{
Evaluation of Emotion Regulation and Associated Characteristics in Foster Children Using the Dyadic Parent-Child Coding System and Caregiver-Report Measures
}

\author{
Meredith A. Norman \\ West Virginia University
}

Follow this and additional works at: https://researchrepository.wvu.edu/etd

\section{Recommended Citation \\ Norman, Meredith A., "Evaluation of Emotion Regulation and Associated Characteristics in Foster Children Using the Dyadic Parent-Child Coding System and Caregiver-Report Measures" (2014). Graduate Theses, Dissertations, and Problem Reports. 247. \\ https://researchrepository.wvu.edu/etd/247}

This Thesis is protected by copyright and/or related rights. It has been brought to you by the The Research Repository @ WVU with permission from the rights-holder(s). You are free to use this Thesis in any way that is permitted by the copyright and related rights legislation that applies to your use. For other uses you must obtain permission from the rights-holder(s) directly, unless additional rights are indicated by a Creative Commons license in the record and/ or on the work itself. This Thesis has been accepted for inclusion in WVU Graduate Theses, Dissertations, and Problem Reports collection by an authorized administrator of The Research Repository @ WVU. For more information, please contact researchrepository@mail.wvu.edu. 


\title{
Evaluation of Emotion Regulation and Associated Characteristics in Foster Children Using the Dyadic Parent-Child Coding System and Caregiver-Report Measures
}

\author{
Meredith A. Norman, B.A. \\ Thesis defense submitted to \\ the Eberly College of Arts and Sciences \\ at West Virginia University \\ in partial fulfillment of the requirements \\ for the degree of \\ Master of Science in \\ Psychology \\ Cheryl B. McNeil, Ph.D., Chair \\ Amy Gentzler, Ph.D. \\ Elisa Krackow, Ph.D. \\ Department of Psychology \\ Morgantown, West Virginia \\ 2014
}

Keywords: Emotion Regulation, Foster Children, Foster Parents, Parenting

Copyright 2014 Meredith Norman 


\begin{abstract}
Evaluation of Emotion Regulation and Associated Characteristics in Foster Children Using the Dyadic Parent-Child Coding System and Caregiver-Report Measures
\end{abstract}

Meredith Norman

The main purposes of this study were to: (a) explore the validity of a relatively new behavioral observation coding system in young children referred for treatment of disruptive behavior, (b) explore which specific foster parent behaviors are most associated with child emotion regulation, and (c) explore whether internalizing or externalizing foster child behavior problems are most associated with child emotion regulation. The sample consisted of 40 foster parent-child dyads who participated in a larger study funded by the National Institutes of Health. Assessments included behavioral observation of child emotion regulation using the Global Dysregulation Scale and a calculation of the percentage of dysregulated 10-second intervals during a clean-up task, parent-report of child emotion regulation using the Emotion Regulation Checklist, parentreport of child behavior problems using the Child Behavior Checklist, and behavioral observation of parent behaviors using the Dyadic Parent-Child Interaction Coding System. Behavioral observation of child emotion regulation was not found to significantly correlate with the Emotion Regulation Checklist. Behavioral observation of parent commands was found to significantly correlate with child emotion regulation measured on the ERC $(r=.38, p=.02)$; however, parent behaviors were not found to correlate with behavioral observation of child emotion regulation. Child internalizing and externalizing behavior problems were not found to correlate with any measures of child emotion regulation. Study findings and implications for future research are discussed. 


\section{Table of Contents}

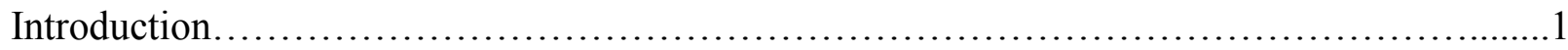

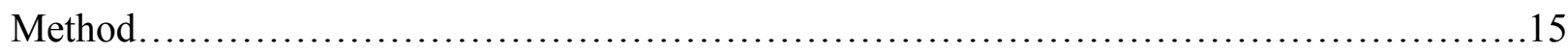

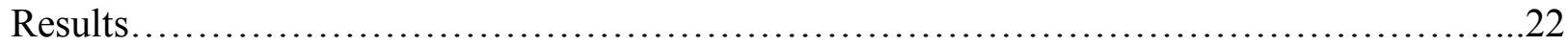

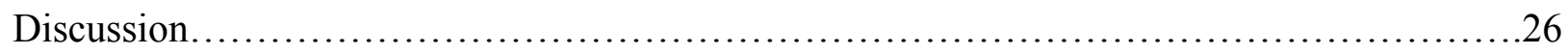

References.................................................................. 35

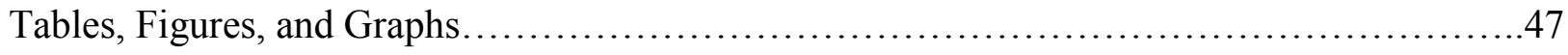




\section{Introduction}

The area of emotion regulation has gained considerable popularity in developmental science and developmental psychopathology research over the past two decades; however, this frequently studied construct lacks a clear and agreed upon definition (Cole, Martin \& Denis, 2004). In part, definitional issues of emotion regulation stem from the existence and acceptance of multiple theories of emotion; with each theory, a different definition of emotion is offered (Cole, et al., 2004, Eisenberg \& Spinrad, 2004; Gross \& Thompson, 2007). Definitions of emotion regulation vary in a number of ways. First, emotion regulation may refer to how emotions are regulated, with a focus on changes in the activated emotion (Cicchetti, Ganiban, \& Barnett, 1991; Gross, 1998; Kopp, 1989; Thompson, 1994). Emotion regulation may also refer to how experience of emotion regulates an individual, with a focus on changes that appear to result from the activated emotion (Cole et al., 2004). Eisenberg and Sprinrad posit that including emotion as regulating in the same construct as emotions as regulated results in a broad construct with reduced usefulness (2004). For this reason, emotion regulation will refer to processes used to manage and change the experience and expression of emotion in this study (Eisenberg, Hofer, \& Vaughan, 2007).

A second definitional disagreement in emotion regulation literature involves whether emotion regulation should include extrinsic processes, regulation from a source outside of an individual, in addition to intrinsic processes, self-regulation. Extrinsic processes make up a significant part of infant and child emotion regulation by way of caregivers shaping and socializing the emotional responses of children (Eisenberg, Spinrad, \& Eggum, 2010; Thompson, 1994). Due to the importance of social context in which children develop skills to manage 
emotions, the definition of emotion regulation adopted by this study will include both intrinsic and extrinsic processes of emotion regulation.

For the purposes of this study, emotion regulation may be defined as the process by which individuals express emotions in circumstantially appropriate, socially acceptable, and individually productive ways (Thompson, 1994). Emotion regulation processes involve dampening, intensifying or maintaining emotional experiences by an individual (Gross \& Thompson, 2007) and determine how the individual expresses these emotional experiences (Gross, 1998). The development of emotion regulation is thought to be related to many aspects of child development such as social competence, peer acceptance, aggressive behavior, externalizing behavior problems, and internalizing behavior problems (Eisenberg, Spinrad, \& Eggum, 2010).

The pathway by which children develop emotion regulation skills and strategies proposed by Calkins (1994) implies that both child individual traits and parent caregiving practices influence the development of emotion regulation in children. Internal sources of regulation include child individual differences in neuroregulatory systems (e.g., endocrine activity; Kagan, Reznick, \& Snidman, 1987), behavioral traits (e.g., temperament; Calkins \& Fox, 1992), and cognitive components (e.g., ability to apply regulation strategies; Dodge, 1991). In addition to internal sources of regulation, development of emotion regulation is influenced by caregiver qualities and the ability of a caregiver to meet the regulatory needs of the child. The development of emotion regulation is interactive, depending on contributions from the child and the caregiver and influenced by their interactions (Cassidy, 1994).

A history of stressful life events (e.g., maltreatment, disruptions in caregivers) may interfere with the neurodevelopment of children in a way that causes disturbances in emotion 
regulation abilities (Gunnar \& Quevedo, 2007). Therefore, the primary goal of the current study is to examine emotion regulation in children who reside in foster care. Accordingly, following introductory sections will discuss processes by which emotion regulation develops, caregiving practices related to child emotion regulation, psychopathology as it results from deficits in emotion regulatory abilities, and child maltreatment, foster care, and emotion regulation difficulties.

\section{Development of Emotion Regulation Skills}

Changes in regulation occur during infancy, with young children shifting from external to internal sources of regulation as they move into toddlerhood (Kopp, 1989). Young infants rely almost entirely on caregivers to modulate their emotional arousal; however, over the first years of life, children gradually learn how to calm themselves through self-regulation, and therefore, rely less on caregivers to meet their regulatory needs. As children mature and become better able to manage emotional responses, parents may use more explicit methods to teach children emotion regulation skills such as modeling and reinforcing appropriate behavior, and providing negative consequences following undesirable behavior (Calkins, 1994).

Although children rely less on caregivers for emotion regulation overtime, children continue to learn regulation skills from their caregivers throughout childhood (Kopp, 1989). It is thought that emotion regulation skills are acquired within a network of social relationships, with caregivers playing a primary role in the learning of these skills (Cole, Martin, \& Dennis, 2004). One way children learn emotion regulation skills from caregivers is through the observation of caregiver displays of emotion (Parke, 1994). Indeed, children learn many behaviors, including those related to displays of emotion, through modeling their caregivers' behavior (Bandura, 1977). The modeling hypothesis of emotion regulation posits that through observing their 
caregivers and their caregivers' interactions with other individuals, children learn about appropriate displays of emotion within the family environment and the ways in which to cope with emotions (Denham, Mitchell-Copeland, Strandberg, Auerbach, \& Blair, 1997).

There are several strategies children have been observed to use to regulate their emotions. A strategy that has been found to be more common for younger children compared to older children is self-soothing (e.g., thumb sucking) (Stansbury \& Zimmermann, 1999). Another strategy children use is distracting themselves from a negative emotion eliciting event either cognitively (i.e., shifting their thinking only) or behaviorally (i.e., engaging in another task) (Gross \& Thompson, 2007). Seeking help from others is considered to be a problem focused strategy that has been found to be associated with better regulation of emotions (Graziano, Calkins, \& Keane, 2011). A strategy more common as children's cognitive abilities develop is reappraising the importance of an event (e.g., thinking a negative event is less significant) or to reappraise the outcome of an event (e.g., thinking about the positive aspects of a negative event) (Davis \& Levine, 2013). The process of emotion regulation depends on the strategies used and the degree to which they are effective.

\section{Caregiving Practices Related to Child Emotion Regulation}

Maternal warmth. One of the caregiving qualities thought to foster child emotion regulation abilities is maternal warmth. Gilliom, Shaw, Beck, Schonberg, and Lukon (2002) provided evidence for the relationship between child emotion regulation and maternal warmth and positivity in a longitudinal study of mothers and their sons. Mother-son dyads were seen when the child was $1 \frac{1}{2}, 3 \frac{1}{2}$, and 6 years of age. Maternal behavior was coded during several laboratory tasks at the $1 \frac{1 / 2}{2}$ year timepoint for counts of verbal approval, physical approval and a global score of maternal warmth. Although this variable was titled positive maternal control by 
the investigators, this aggregation of scores is also an indication of the general warmth and positivity expressed by the mothers towards their children. Child emotion regulation strategy use was assessed at the $3 \frac{1}{2}$ year timepoint during an emotion eliciting task. The investigators found that positive maternal control, or warmth and positivity, assessed at the $1 \frac{1 / 2}{2}$ year timepoint was positively correlated with more effective child emotion regulation strategy use at the $3 \frac{1}{2}$ year timepoint.

Negative maternal control. Whereas positive maternal control is associated with greater child emotion regulation (Gilliom et al., 2002), poorer emotion regulation outcomes have been observed in children whose mothers exert high levels of negative maternal control. In a study conducted by Calkins, Smith, Gill and Johnson (1998), observational coding of interactions between mothers and their 24 month-old toddlers was utilized to examine the relationship between maternal negative control and child emotion regulation strategies. The total maternal negative control score was derived from an aggregation of observational scores for negative control (e.g., scolding), physical control (e.g., restricting child movement), and verbal control (e.g., directing child activity). Child emotion regulation strategies employed by the children in this study during negative emotion eliciting tasks were also coded. Calkins et al. found that maternal negative control was negatively correlated with adaptive emotion regulation strategy use in these toddlers. Thus, maternal negative control is one negative parenting practice associated with poor emotion regulation abilities in young children.

\section{Psychopathology Related to Child Emotion Regulation Difficulties Externalizing Behavior Problems}

Current literature suggests that externalizing behavior is one of the several negative child outcomes related to poor child emotion regulation. A study by Chang, Schwartz, Dodge, and 
McBride-Chang (2003) found that child emotion regulation mediated the relationship between harsh parenting and child aggressive behavior in the school setting. Another study by Teisl and Cicchetti (2007) that compared physically abused children to a control group of non-maltreated children found that emotion regulation significantly predicted aggression and disruptive behavior for both groups of children. Furthermore, the investigators found that emotion regulation mediated the relationship between physical abuse and aggression as well as disruptive behavior in the maltreated group of children. Finally, a study by Rydell, Berlin and Bohlin (2003) found that poor regulation of anger and positive emotions when the children in the study were 5 and 6 $1 / 2$ years of age predicted externalizing behavior problems when the children were 8 years of age. Together, these findings provide evidence for the relationship between child emotion regulation and externalizing behavior.

\section{Internalizing Behavior Problems}

A relationship between child internalizing behavior and emotion regulation has also been identified in the literature. Unlike children who exhibit externalizing behaviors associated with underregulation of emotions, children who exhibit internalizing behaviors are characterized as having unspontaneous and overly controlled responses to emotional experiences (i.e., overregulation; Eisenberg \& Fabes, 1992). In a study conducted by Cole, Zahn-Waxler, Fox, Usher, and Welch (1996), children were shown short video clips designed to elicit negative emotions; observational codes of child facial expressions while viewing the clips were used as a measure of child emotion regulation. The investigators categorized children who displayed low levels of emotional response to the videos as being overregulated; furthermore, they found depressive and anxious symptoms were more likely in this group of children. These findings 
indicate that there is a relationship between child emotion regulation and internalizing behaviors in children.

A common model put forth by researchers to explain the development of internalizing behaviors in young children involves child emotion regulation mediating the relation between temperament and adjustment outcomes (Yap, Allen, \& Sheeber, 2007). Specifically, children who are behaviorally inhibited are more likely to use passive emotion regulation strategies than uninhibited children; furthermore, children who use passive emotion regulation strategies are more likely to develop internalizing behaviors. Research conducted by Feng and colleagues provide support for the proposed model in that certain emotion regulation strategies (e.g., passive waiting and comfort seeking) utilized by shy, young children are found to be associated with internalizing behaviors later in childhood (Feng, Shaw, \& Silk, 2008). Additionally, passive emotion regulation strategies observed at age 3.5 years were found to mediate the relation between early shyness and later maternal and teacher report of internalizing behaviors (Feng, Shaw, \& Moilanen, 2011). Thus, the research conducted by Feng and colleagues provides support for the proposed model that emotion regulation mediates the relation between child temperament and adjustment outcomes.

\section{Child Maltreatment, Foster Care and Emotion Regulation}

Child maltreatment commonly results in child emotion regulation difficulties for a number of reasons. First, maltreating mothers have been found to respond inappropriately to child expressions of emotion. For example, Frodi and Lamb (1980) found that the 14 maltreating mothers participating in the study reported more aversion and less sympathy towards their crying infants than the matched group of 14 non-maltreating mothers. Additionally, Shipman et al. (2007) found that a group of 40 maltreating mothers, compared to a group of 40 non-maltreating 
mothers, displayed less appropriate responses to their children's expression of negative emotion by providing their children with more invalidation of emotions, less validation of emotions, and less emotional coaching.

Second, maltreating mothers provide their children with poor socialization of emotions. Maltreating mothers often have poor emotion regulation themselves and thus serve as poor models of emotion regulation and emotion managing strategies (Cummings \& Davies, 1996; Shipman et al., 2007). Third, maltreating families are characterized by high levels of conflict which contribute to a negative and unpredictable emotional climate within the family environment (Morris, Silk, Steinberg, Myers, \& Robinson, 2007). Children who are raised in a negative emotional climate are at a greater risk of becoming highly emotionally reactive which interferes with a child's ability to regulate emotions (Cummings \& Davies, 1996).

Shipman et al. (2007) found that physically maltreated children exhibited fewer adaptive emotion regulation skills and demonstrated more emotion dysregulation compared to nonmaltreated children. Specifically, mothers reported that their maltreated children expressed greater emotional lability and negativity. They also reported that their children exhibited fewer appropriate emotional displays and lower levels of empathy and emotional self-awareness. Maughan and Cicchetti (2002) also found maltreated children to be more emotionally dysregulated than their non-maltreated peers. When children witnessed a scripted angry exchange between a research assistant and their mothers, $80 \%$ of maltreated children displayed dysregulated emotion patterns compared with $36 \%$ of the non-maltreated children. These studies highlight the negative impact maltreatment has on child emotion regulation.

Research by Cicchetti suggests that emotion regulation may mediate the relation between child maltreatment and child behavior problems. In a study conducted by Teisel and Cicchetti 
(2008), child emotion regulation was found to partially account for the relation between physical abuse history and disruptive behavior problems. This line of research was extended in a study conducted by Alink, Cicchetti, Kim, and Rogosch (2009) which found that emotion regulation partially mediated the relation between maltreatment history and both internalizing and externalizing psychopathology. Furthermore, the quality of mother-child relationships moderated this mediated relation in that emotion regulation was found to mediate the relation between maltreatment history and psychopathology for children with insecure patterns of relatedness to their mother but not for children with secure patterns of relatedness to their mother. For children with a secure pattern of relatedness with their mother, maltreatment history was found to be unrelated to emotion regulation ability. The authors describe secure patterns of relatedness as a protective factor that may reduce the impact of child maltreatment on regulatory abilities and developmental of psychopathology. This research highlights the important role emotion regulation has in the development of child behaviors problems for children who have experienced maltreatment, especially for those children with insecure patterns of relatedness to their mother.

Children in foster care are at greater risk for emotion regulation difficulties given the likelihood that they have experienced maltreatment. Foster children are at an additional risk for emotion regulation problems as a consequence of experiencing disrupted relationships with caregivers (Calkins, 1994). Given that foster children are at risk for developing poor emotion regulation skills, researchers have recently become interested in foster parent variables that may serve as protective factors that promote emotion regulation in foster children.

Two such studies have been conducted to date; however, methodological problems within these studies limit their ability to address the relationship between foster parent variables and 
child emotion regulation. The first study was conducted by Robinson et al. (2009) and assessed the emotion regulation abilities of 66 children who had previously been maltreated and were currently in foster care. Specifically, these children were coded on observational emotion regulation scales during several parent-child interaction tasks with their biological mothers. Analyses revealed no significant differences in emotion regulation variables based on the length of time the child had spent in foster care. However, without measurement of foster parent variables related to emotion regulation, such as foster parent warmth, sensitivity, modeling of emotion regulation and expressions of negativity, one cannot assume foster care encouraged the development of child emotion regulation abilities nor expect there to be a relationship between amount of time in foster care and emotion regulation abilities. Additionally, child emotion regulation was assessed during interactions with the children's biological mothers who typically were the perpetrators of maltreatment against these children. The presence of their mothers may have caused some children whose mothers maltreated them to become more emotionally reactive and less able to regulate their emotions. Under these circumstances, the emotion regulation assessment strategy used in this study may not have been appropriate for addressing the relationship between foster parent variables and child emotion regulation.

The second study conducted by Healey and Fisher (2011) examined the relationship between parenting practices of foster parents and the emotion regulation of foster children. The sample for this study consisted of 35 children in foster care who were between 3 and 5 years of age and part of a larger longitudinal study conducted by the Oregon Social Learning Center. Foster parenting practices were assessed using the Parenting Scale (Arnold, O'Leary, Wolff, \& Acker, 1993), a self-report measure of dysfunctional parenting practices designed for families with young children. Child emotion regulation was assessed when the children were between 7 
and 11 years old using the Emotion Regulation Checklist. The ERC was completed by foster parents or assessment staff three times over a 12 month period to provide a clearer picture of child emotion regulation ability.

Their study did not find a significant correlation between foster parenting practices and later child emotion regulation; however, there are several methodological limitations of this investigation that preclude definitive conclusions. The authors hypothesized that assessment of parenting practices using a self-report measure may not have accurately measured negative and ineffective parenting; foster parent scores may have reflected their parenting values rather than their actual behaviors. Additionally, placement stability was not taken into account during analyses; therefore, it is possible that the children in this study spent only a short amount of time with the foster parent who completed the Parenting Scale. If this was the case, one would not expect there to be a relationship between the parenting practices of a foster parent with whom a child resided with for only a brief period of time and later child emotion regulation. Finally, there are several shortcomings of the sample utilized in this study that could have produced results that may not generalize to a more diverse population. One of the shortcomings of the sample was its size with only 35 participants. Secondly, two important demographic characteristics of this sample, ethnicity and residency, were not reflective of the greater American population; 33 of the sample's 35 participants were European American and all were residents of Oregon. It is, therefore, clear that more research is needed to explore the relationship between foster parent variables and child emotion regulation.

\section{Measurement of Emotion Regulation During Clean-up Tasks}

One way investigators assess child emotion regulation is through observing child behavior during challenging tasks (Cole, Martin, \& Dennis, 2004). A clean-up task is a 
procedure utilized in emotion regulation literature to assess child emotion regulation in which the child is instructed to clean up toys following a free play period (Hoffman, Crnic, \& Baker, 2006). The clean-up task is most commonly used to assess child compliance; however, instructing a child to put away toys that the child is still interested in playing with presents an emotional challenge that frequently elicits negative emotions, and thus, provides an opportunity for researches to assess child emotion regulation. In a study conducted by Rodriguez, Graziano, Bagner, and Hernandez (2011), the investigators utilized the Global Regulation observational scale to assess child emotion regulation during the Child-Directed Interaction (CDI) and CleanUp situations of the Dyadic Parent-Child Interaction Coding System (DPICS; Eyberg, Nelson, Duke, \& Boggs, 2005), a standard parent-child interaction observation procedure. The investigators found that children who received higher scores on the Global Regulation scale, indicating better regulation, had less change in cortisol levels from CDI to the Clean-Up situation. These findings provide preliminary evidence for the validity of the Global Regulation scale when used to assess child emotion regulation during the DPICS Clean-Up task.

\section{The Current Study: Measurement of Foster Child Emotion Regulation in a Therapeutic}

\section{Context}

Observations that occur in a therapeutic context can provide naturalistic information regarding the regulatory abilities of children referred for treatment. Although the negative child outcomes found in children who have experienced maltreatment are well known in the literature (Kim \& Cicchetti, 2010), little is known about the foster parent and child variables associated with emotion regulation difficulties in foster children. Children in this study were referred for Parent-Child Interactions Therapy (Eyberg, 1988; McNeil \& Hembree-Kigin, 2010), an evidence-based treatment for behavior problems in children who have been abused (Chaffin et 
al., 2004). A standard observation procedure used in all cases of PCIT is called the Dyadic Parent-Child Interaction Coding System (DPICS; Eyberg, Nelson, Duke, \& Boggs, 2005). In this study, the clean-up portion of the DPICS is used as a frustration task and coded using the Global Regulation observational scale (Calkins \& Dedmon, 2000; Winslow, Shaw, Bruns, \& Kiebler, 1995); thus, the first purpose of this study was to explore the validity of a relatively new behavioral observation coding system in young children referred for treatment of disruptive behavior. As the DPICS is a well-established and commonly used behavioral observation system in community health settings, the application of the Global Regulation behavioral observation scale to the DPICS clean-up situation was hypothesized to provide valuable information about the relationship between parent and child behaviors and child emotion regulation.

An additional purpose of this study was to explore which specific foster parent behaviors are most associated with child emotion regulation. Parenting behaviors were coded during the DPICS child-led and parent-led play situations. To date, few studies have examined the relationship between foster parent behaviors and foster child emotion regulation; furthermore, there were serious methodological issues in these previous studies. The proposed study was designed to expand the literature on the relationship between foster parent behaviors and child emotion regulation. The final purpose of this study was to explore which foster child variables are most associated with child emotion regulation. The specific variables proposed to be examined in this study, externalizing and internalizing behavior problems, were selected based on previous research in the area of child emotion regulation.

\section{Exploratory Questions}

\section{Exploratory Question 1}


Is the observational Global Regulation scale a valid measure of child emotion regulation during the clean-up portion of the DPICS assessment?

To date, only one study has examined the validity of the observational Global Regulation scale during the DPICS clean-up situation. Rodriguez et al. (2011) found a significant relationship between the Global Regulation scale scores and child cortisol levels, indicating that the Global Regulation scale may be a valid measure of child regulation that can be applied to the DPICS clean-up task. The proposed study examined the validity of the Global Regulation scale during this task.

\section{Exploratory Question 2}

What specific foster parent behaviors observed during the child-led and parent-led play DPICS are most associated with foster child scores on the Emotion Regulation Checklist as well as scores on the Global Regulation scale and the percentage of dysregulated intervals during clean-up?

There is a lack of literature on the relationship between foster parent behaviors and child emotion regulation; therefore, no specific hypotheses regarding this relationship were put forth for this study. The variables measured during the child-led and parent-led DPICS situations were selected for the proposed study based on the existing literature in the areas of maternal warmth and negative maternal control. Maternal warmth is operationalized in the literature as a combination of verbal and physical approval; therefore, positive verbal statements made by foster mothers and positive physical contact between foster mothers and the foster children were examined. Maternal negative control has been operationalized in the literature as negative control, physical control, and verbal control; therefore, negative statements made by foster 
mothers, negative physical contact between foster mothers and the foster children, and commands directed towards the foster children were examined.

\section{Exploratory Question 3}

What child variables (i.e., internalizing and externalizing behavior problems) are most associated with foster child scores on the Emotion Regulation Checklist as well as scores on the Global Regulation scale and the percentage of dysregulated intervals during clean-up?

Specific hypotheses regarding the relationship between foster child behavior problem variables and emotion regulation were not proposed because of the limited research in this area. The foster child variables of internalizing and externalizing behavior problems were selected for the proposed study were selected based on the existing research on non-foster parents and nonfoster children available in the literature.

\section{Method}

\section{Participants}

The sample consisted of 40 foster parent-child dyads who participated in a larger study funded by the National Institutes of Health. This study is being conducted by principle investigators Drs. Mersky and Topitzes at the University of Wisconsin, Milwaukee in collaboration with co-principal investigator, Dr. Cheryl McNeil at West Virginia University. This larger project examined the efficacy of adaptations to PCIT with foster children and their foster parents.

The Bureau of Milwaukee Child Welfare (BMCW) was used to identify licensed, nonrelative foster parents who are caregivers for a foster child 3 through 6 years of age. The Eyberg Child Behavior Inventory (ECBI; Eyberg, \& Pincus, 1999), a measure of child disruptive and externalizing behaviors, was completed by potential foster parent participants and used as a 
screening tool to select children who exhibit above average behavior problems compared to nonclinical sample norms. Foster children were not required to have a diagnosis of ODD to be included in the study. This sample is a high risk, homogeneous group of children predisposed towards dysregulation. To reduce the likelihood of placement change during the study, cases nearing adoption or reunification were contacted to participate. Additionally, children with developmental disabilities were excluded from this study. Finally, if multiple children from one foster home met the study criteria, only one child from this family was chosen at random to participate. All participants received the same pretreatment assessment.

Demographic data on foster child age, foster parent age, and foster parent highest education level were analyzed for the 40 participants in this study. Table 1 displays the mean and standard deviations for foster child and foster parent age. The average age of the foster children in this study was 5.05 years $(S D=1.09)$. The average age of the foster parents in this study was 46.57 years $(S D=11.75)$. Table 2 displays the count of foster child and foster parent gender and race. This sample included 16 male and 24 female foster children. Four of the foster parents were male while 36 of the foster parents were female. Twenty-two of the foster children were African American, nine were Caucasian, six identified as "mixed" or "other", two were Hispanic, and one was Asian. Twenty-three of the foster parents were Caucasian, 13 were African American, and four identified as "mixed" or other". This sample included foster parents whose highest levels of education were the following: two (5\%) foster parents had some high school education; four (10\%) foster parents had a high school diploma or G.E.D.; fifteen (37.5\%) foster parents graduated from high school and attended some college courses, technical school, or vocational training; five (12.5\%) foster parents graduated from college; 6 (15\%) foster parents took part in some post graduate work; five (12.5\%) foster parents obtained a graduate degree. 
The following child variables were proposed for analyses; however, this data was not collected by the principle investigators of Project Connect: type of maltreatment experienced, amount of time spent in foster care relative to age, and amount of time living with the current foster mother relative to age. Additionally, foster parent SES was proposed for analyses, but was not collected by the principle investigators of Project Connect.

\section{Procedure}

Once a foster parent and child dyad was deemed to meet the study criteria, researchers collected signed consent forms from the child's legal custodian and obtained caregiver assent for the child. The dyads then took part in a baseline assessment. During the baseline assessment, parents completed self-report measures using the Questionnaire Development System software and Audio Computer-Assisted Self-Interviewing technology, if needed, on a computer. Research assistants then conducted observations of the parent and child at the HBSSW in clinical training rooms using two-way mirrors and video recording equipment. These baseline assessments lasted approximately one hour, and then parents were given \$20 for their participation in the data collection. In the larger study, data were collected pre-treatment and post-treatment; however, the proposed study only examined data collected during this initial baseline assessment.

All coding in this study was conducted from transcribed video recordings. One graduate student and two undergraduate students were trained to code parent behaviors during parentchild observations. The same graduate student and a different undergraduate student were trained to code child emotion regulation during parent-child interactions. Training included a series of didactics, homework assignments, and evaluations. After the training, the raters coded live or videotaped interactions. Coders were considered reliable after attaining an agreement of .75 Kappa for each of the dependent variables on three consecutive observations. Inter-rater 
agreement will be attained for $20 \%$ of the study observations. Data from Project Connect was obtained in electronic format through PantherFile, a secure online file transfer website. Both video and data files were designated a unique identifier to protect the confidentiality of the participants. This proposed study was approved by the IRB.

\section{Measures}

\section{Demographic Form}

The foster parents completed a demographic questionnaire that includes foster parent age, length of time the individual has been a foster parent, number of children being fostered in the home, total number of children in the home, number of adults in the home, relationship status, occupation, partner occupation, education level, and race/ethnicity. The demographic information collected for the foster children include age, gender, race/ethnicity, diagnosis of disability or medical condition, and information related to maltreatment allegation.

\section{Dyadic Parent-Child Interaction Coding System}

The Dyadic Parent-Child Interaction Coding System (DPICS; Eyberg, Nelson, Duke, \& Boggs, 2005) is an observational measure of parent and child behaviors including several verbalizations, vocalizations, and physical behaviors that maintain particular parent-child interaction patterns. The DPICS observations are conducted in 5-minute parent-child interaction situations that vary in exertion of parental control. The foster parent observational codes to be used in the proposed study will be obtained from the child-led play and parent-led play situations. At the start of the child-led play, the parent is instructed to allow the child to choose an activity and to follow the child's lead in play. Following the child-led play situation, the parent-led play begins with the parent receiving instructions to choose an activity and to keep the 
child playing according to the parent's rules. Observational codes were aggregated across the two situations to obtain total foster parent behavior scores for each category of behavior.

Parent behaviors coded using the DPICS are organized into several categories. The study examined the following parent categories: positive talk, negative talk, positive touch, negative touch, commands, and percent of no opportunity for compliance commands. The positive talk score is an aggregate of parental labeled praises, unlabeled praises and reflections. Labeled praises express a positive evaluation of a specific behavior or product of the child, while unlabeled praises express a positive evaluation of the child, an attribute of the child, or a nonspecific behavior or product of the child. Finally, reflections are statements that have the same meaning as a child verbalization. The negative talk score is derived from the number of statements expressing disapproval of the child or the child's actions. The physical touch score is derived from coding of physical contact between parent and child other than accidental touch; each physical contact is coded as either positive or negative. The command score is derived from the number of commands given by the parent. A command is defined as a statement that directs the verbal or physical behavior of another person. The final category, percent of no opportunity for compliance commands, is the number of no opportunity commands given by the parent expressed as a proportion of the total number of commands. A no opportunity for compliance command is defined as a command given for which the child is not given an adequate chance to comply. Vague commands and commands for unobservable behavior are both examples of no opportunity for compliance commands.

The DPICS categories have demonstrated reliability and validity for both live and video recorded observations (Eyberg et al., 2005; Robinson \& Eyberg, 1981). The categories of parent Negative Talk and Praise coded during the parent-led play and clean-up situations were found to 
have significant stability over a one week period providing evidence for the test-retest reliability of the measure (Eyberg et al., 2005). Additionally, the measure has demonstrated discriminant validity by distinguishing between referred and non-referred mother-child dyads (Robinson \& Eyberg, 1981). The DPICS has also demonstrated convergent validity with the ECBI Intensity score, PSI Child Domain score, PSI Parent Domain score, and PSI Parental Locus of Control score (Eyberg et al., 2005; Webster-Stratton, 1985).

\section{Behavioral Observation of Child Emotion Regulation: Global Dysregulation Scale} and Percent of Intervals in which Emotion Dysregulation Occurs

Emotion regulation behavioral observation scores were obtained from video recordings of the DPICS clean-up situation, which takes place after the DPICS child-led and parent-led situations. At the start of this situation, the parent was instructed to have the child put away the toys without help from the parent. Child emotion regulation was coded using the Global Dysregulation observational scale (Calkins \& Dedmon, 2000; Winslow, Shaw, Bruns, \& Kiebler, 1995) and by calculating the percentage of 10 -second intervals in which the child displays dysregulation of emotions during the clean-up task. Dysregulation was defined as the inability to decrease distress during a negative emotion eliciting task (Hill, Degnan, Calkins, \& Keane, 2006). On the 5-point scale Global Dysregulation scale, a score of 4 indicates that the child is emotionally dysregulated and unable to control distress and a score of 0 indicates that the child is emotionally well regulated and able to control distress throughout most of the task. The percentage of 10-second intervals in which each child displays emotion dysregulation was also calculated. Reliability Kappas of .83 for the Global Dysregulation observational coding system were reported for a study conducted by Hill et al. (2006) providing evidence for inter-rater reliability of the coding system. 


\section{Emotion Regulation Checklist}

The Emotion Regulation Checklist (ERC; Shields \& Cicchetti, 1997) is a parent-report measure designed to assess perception of child regulation and emotionality. The instrument consists of 24 items describing child behaviors that are rated on a 4-point Likert-type scale with a frequency response format $(1=$ almost always to $4=$ never $)$. Factor analysis conducted by Shields and Cicchetti (1998) revealed two subscales, Emotion Regulation subscale and LiabilityNegativity subscale. The Emotion Regulation subscale consists of items that assess child adaptive regulation and appropriate displays of emotion. An example of an item from this subscale is "Can say when she/he is feeling sad, angry or mad, fearful or afraid." The LiabilityNegativity subscale consists of items that assess child negative reactivity, emotional intensity, and dysregulation of positive emotions. An example of an item from this subscale is "Exhibits wide mood swings." The aggregation of these two subscales produces an emotion regulation composite score that captures both regulation and dysregulation of emotions. Shields and Cicchetti (1997) reported a high internal consistency for the ERC total score and the two subscale scores with a Cronbach's alpha of .89 for the composite ERC score, .83 for the Emotion Regulation subscale, and .96 for the Liability-Negativity subscale. The ERC has demonstrated convergent validity with a behavioral observation coding system designed to assess emotion regulation in children (Shields \& Cicchetti, 1997).

\section{Child Behavior Checklist}

The Child Behavior Checklist (CBCL; Achenbach \& Rescorla, 2001) is a parent-report measure designed to assess child behavior problems. The version of the instrument administered was based on the target child age. Foster parents of 6 year old participants completed the version for 6 to 17 year olds and the foster parents of child participants under the age of 6 completed the 
version for children between 1.5 and 5 years of age. Items are scored on a 3 point scale with respondents indicating how true each item is of the target child. In the proposed study, Externalizing and Internalizing scales were utilized. The Externalizing scale includes behavior problems related to aggression and attention problems, while the internalizing scale includes behavior problems related to emotional reactivity, anxious/depressed symptoms, somatic complaints, and withdrawn behavior.

The CBCL is considered to be a reliable and valid measure of child behavioral and emotional functioning (Achenbach \& Rescorla, 2001). Evidence has been demonstrated for the measure's internal consistency with an obtained alpha of .94 for the Externalizing scale and .90 for the Internalizing scale. Additionally, test-retest Pearson correlations for the total score have been found to range from .95 to 1.0 and interrater reliability is reported to range from .93 to .96 .

\section{Results}

Before conducting analyses, Kappa values were examined for the foster parent DPICS composite dependent variables and the emotion regulation observational measures. Kappa values ranged from .76-.83 for the positive verbal composite, from .78-.86 for the negative verbal composite, from .89-.93 for the positive touch composite, from .85-.87 for the negative touch composite, from .75-.88 for the command composite, and from .87-.93 for the percentage no opportunity commands composite. Kappa values were .89 for the Global Dysregulation observational scale and .78 for the percentage of dysregulated intervals.

Missing data were analyzed and handled in an appropriate manner by imputing values according to the specifications in the manual for the each measure. For the CBCL, greater than eight missing problem scale items renders problem scale scores uninterpretable. Nine children had fewer than eight missing items for the CBCL problem scales; none of the children had 
greater than eight missing problem scale items. Five of the children were missing items for the ERC. One child was missing three items, three children were missing two items, and one child was missing one item on the ERC. There were no missing data for the behavioral observation DPICS and emotion regulation coding variables. Preliminary analyses were conducted to ensure there were no violations of the assumptions of normality or linearity. The Emotion Regulation Checklist (ERC) and Child Behavior Checklist (CBCL) Internalizing and Externalizing scales were normally distributed for this sample. The DPICS positive and negative verbal composites, DPICS positive and negative touch composites, Global Dysregulation observational scale, and percentage of observed dysregulated intervals violated assumptions of normality, and were all square-root transformed. After being square-root transformed, the DPICS positive and negative touch composites and Global Dysegulation observational scale still violated assumptions of normality. Therefore, these three variables were log transformed. The DPICS positive and negative touch composites continued to violate assumptions of normality after this transformation; therefore, analyses using these variables should be interpreted with caution.

The first exploratory question of this study addressed the validity of the Global Dysregulation observational coding scale as a measure of child emotion regulation during the clean-up portion of the DPICS assessment. Table 3 displays the means and standard deviations for the emotion regulation measures in this study. To determine the concurrent validity of the Global Dysregulation observational scale with the most commonly used measure for child emotion regulation, the Emotion Regulation Checklist, the bivariate correlation between the ERC and the Global Dysegulation scale as well as the percentage of observed dysregulated intervals were examined and are presented in Table 4. The ERC and the Global Dysregulation scale were 
not significantly correlated, $r=-.16, p=.35$. The ERC and the percentage of observed dysregulated intervals were also not significantly correlated, $r=-.17, p=.319$.

The second exploratory question of this study addressed the relation between specific foster parent behaviors observed during the child-led and parent-led play DPICS situations (i.e., positive talk, negative talk, positive touch, negative touch, commands, percent of no opportunity for compliance commands) and the Global Dysregulation observational scale and percentage of observed dysregulated intervals during clean-up. Table 5 displays the means and standard deviations for foster parent behavior composites during child-led and parent-led play. To evaluate the relationship between the foster parent behaviors and child emotion regulation, the bivariate correlations (between foster parent behavior variables and child ERC scores, Global Dysregulation observational scale, and percentage of observed dysregulated intervals) were examined and can be found in Table 6.

Foster parent positive and negative talk composites were not significantly correlated with measures of child emotion regulation. Specifically, foster parent positive talk composite for child-led play and parent-led play was not significantly correlated with the ERC, $r=.14, p .40$, with the Global Dysregulation scale during clean-up, $r=.22, p=.18$, or with the percentage of dysregulated intervals during clean-up, $r=.22, p=.17$. Additionally, foster parent negative talk composite for child-led play and parent-led play was not significantly correlated with the ERC, $r$ $=-.01, p=.96$, with the Global Dysregulation scale during clean-up, $r=-.20, p=.22$, or with the percentage of dysregulated intervals during clean-up, $r=-.17, \mathrm{p}=.29$.

Foster parent positive and negative touch composites were not significantly correlated with measures of child emotion regulation. Specifically, foster parent positive touch composite for child-led play and parent-led play was not significantly correlated with the ERC, $r=.13, p=$ 
.442, with the Global Dysregulation scale during clean-up, $r=-.04, p=.81$, or with the percentage of dysregulated intervals during clean-up, $r=.01, p=.65$. Additionally, foster parent negative touch composite for child-led play and parent-led play was not significantly correlated with the ERC, $r=.23, p=.18$, with the Global Dysregulation scale during clean-up, $r=.16, p=$ .34 , or with the percentage of dysregulated intervals during clean-up, $r=.14, p=.39$.

Foster parent command composite and percentage of no opportunity commands composite were found to moderately correlate with the ERC, but not with observational measures of child emotion regulation. Specifically, foster parent command composite for childled play and parent-led play was moderately correlated with the ERC, $r=.38, p=.02$, not correlated with the Global Dysregulation scale during clean-up, $r=-.10, p=.53$, and not correlated with the percentage of dysregulated intervals during clean-up, $r=-.12, p=.50$. Additionally, foster parent percentage of no opportunity commands composite for child-led play and parent-led play was moderately correlated with the ERC, $r=.32, p=.05$, not correlated with the Global Dysregulation scale during clean-up, $r=-.16, p=.32$, and not correlated with the percentage of dysregulated intervals during clean-up, $r=-.18, p=.26$. Because only one foster parent variable, command composite, was found to significantly correlate with a measure of child emotion regulation, a multiple regression was not conducted for this exploratory question to examine which foster parent behavior is most associated with child emotion regulation.

The third exploratory question of this study addressed the association between child internalizing and externalizing problem behaviors assessed through caregiver-report method on the CBCL and child emotion regulation on the ERC as well as the Global Dysregulation scale and percentage of dysregulated intervals during clean-up. The means and standard deviations for the CBCL internalizing and externalizing problem behavior scales are presented in Table 7 while 
the correlations between the internalizing and externalizing CBCL scales and the measures of emotion regulation are presented in Table 8. There was a statistical trend suggesting that the child internalizing behavior problems on the CBCL may be moderately correlated with the ERC, $r=-.31, p=.06$. Child internalizing behavior problems was not correlated with the Global Dysregulation scale during clean-up, $r=.08, p=.63$ and not correlated with the percentage of dysregulated intervals during clean-up, $r=.09, p=.61$. Child externalizing behavior problems on the CBCL was not correlated with the ERC, $r=-.09, p=.59$, not correlated with the Global Dysregulation scale during clean-up, $r=.14, p=.43$, and not correlated with the percentage of dysregulated intervals during clean-up, $r=.17, p=.32$. Because neither the internalizing CBCL scale nor the externalizing CBCL scale was found to correlate with a measure of child emotion regulation, a multiple regression was not conducted for this exploratory question to examine which type of child behavior problem is most associated with child emotion regulation.

\section{Discussion}

The main purposes of this study were to: (a) explore the validity of a relatively new behavioral observation coding system in young children referred for treatment of disruptive behavior, (b) explore which specific foster parent behaviors are most associated with child emotion regulation, and (c) explore whether internalizing or externalizing foster child behavior problems are most associated with child emotion regulation. Behavioral observation of child emotion regulation was not found to significantly correlate with the Emotion Regulation Checklist. Behavioral observation of parent commands was found to significantly correlate with child emotion regulation measured on the ERC $(r=.38, p=.02)$; however, parent behaviors were not found to correlate with behavioral observation of child emotion regulation. Child internalizing and 
externalizing behavior problems were not found to correlate with any measures of child emotion regulation.

\section{Validity of Global Dysregulation Scale During the DPICS Clean-up Task}

In this study, the Emotion Regulation Checklist was not found to correlate with behavioral observations of child emotion regulation. It is worth noting that there appears to be a floor effect for emotion regulation observed during the DPICS clean-up task. The majority of the children in the sample scored a 0 on the Global Dysregulation scale indicating no emotion dysregulation (see Graph 1); additionally, the majority of the children in the sample had less than $20 \%$ of intervals in which dysregulation occurred during the clean-up task (see Graph 2). Low frequency and intensity of child emotion dysregulation during the clean-up task could be explained one of three ways. First, it is possible that the clean-up task did not elicit negative emotions in this sample of children; thus, emotion regulation could not be observed. Although other studies examining child emotion regulation have included a clean-up task to elicit negative emotions in children (e.g., Hoffman, Crnic, \& Baker, 2005), other frustrating tasks are often included to create a composite index of emotion regulation. Second, it is possible that the children in this sample experienced a negative emotional state during clean-up and were able to regulate their emotions quite effectively. The second explanation seems less likely given that the sample of children in this study were reported to be engaging in clinical levels of disruptive behavior problems and given the association between externalizing behavior problems and emotion regulation difficulties in the literature (Eisenberg et al., 2001). Finally, it is possible that foster parents are not accurate reporters of foster child behavior problems and emotion regulation abilities, thereby rendering the ERC less valid in this population. 
There are several potential methodological explanations for why the clean-up task may not have elicited negative emotions in the children in this sample. One such explanation is that child emotion regulation observed during the baseline session of Project Connect lacks ecological validity because it took place in an environment novel to the children in the study. Indeed, the children were unfamiliar with the physical space in which they took part in the three DPICS situations and it is possible that the toys were novel for many of the foster children. Cole and colleagues (2004) note the conceptual and practical importance of eliciting a negative emotional reaction in children in order to observe children's ability to regulation their emotions. Potentially, the excitement of an unfamiliar space, novel toys, and undivided parental attention may have prevented the children from experiencing the negative emotions often associated with having to clean-up toys.

Additionally, the undivided attention of caregivers in the DPICS clean-up situation may have helped the children in this study regulate their emotions. Indeed, children are better able to regulate their emotions when they engage in emotion regulation strategies with their caregiver. A study conducted by Morris, Silk, Morris, and Steinberg (2011) found that mother-child emotion regulation strategies utilized during a laboratory task that elicited disappointment were associated with reduced expressions of anger and sadness in children. Laboratory tasks such as the DPICS clean-up situation minimize typical real-world demands placed on parents (e.g., ringing telephones, children who need to be fed dinner). With fewer demands placed on parents in laboratory tasks, parents may be more likely to (a) anticipate or notice child dysregulation and (b) have greater cognitive resources available to help their child regulate their emotions than they have in their typical environment. Thus, greater than usual parental attention potentially provided during the DPICS clean-up situation may account for a lack of relationship between 
observations of emotion regulation during a laboratory task and foster parent-report of typical child emotion regulation.

There is no existing literature on the reliability of foster-parent report of child emotion regulation; however, studies have been conducted on the reliability of foster parent report of child behavior problems. The reliability of foster-parent report of child behavior problems may shed light on the ability of foster parents to report on child psychological constructs more generally. A study conducted by Randazzo, Landsverk, and Ganger (2003) compared biological parent, foster parent, and teacher-report for internalizing and externalizing behavior problems in a group of 5 and 6-year-old children. The results of the study suggest that biological parent psychopathology was associated with their report of child behavior problems; however, parent psychopathology was not found to be associated with foster parent or teacher-report of child behavior problems. The authors suggest that foster parents have a unique perspective into child behavior problems because they are able to objectively observe a child in their home environment and across a number of situations. A similar study conducted by Tarren-Sweeney, Hazell, and Carr (2004) examined the interrater reliability between foster parent and teacherreport of child behavior problems. The authors found that foster parents and teachers had moderate to good agreement for child total problems and externalizing problems, while they had poor agreement for child internalizing behavior problems. In general, greater discrepancy between reporters has been found for child internalizing behavior problems than other types of behavior problems (Achenbach, McConaughy, \& Howell, 1987; De Los Reyes \& Kazdin, 2005). Taken together, the literature suggests that while there is some degree of discrepancy between other-reports of child behavior problems, foster parents and teachers have acceptable reliability in reporting total behavior problems and externalizing behavior problems, and less acceptable 
reliability in reporting internalizing child behavior problems. It is possible that like internalizing behavior problems, emotion regulation is a construct based on internal processes that are difficult to assess through questionnaire format regardless of the reporter.

\section{Association between Foster Parent Behaviors and Child Emotion Regulation}

Foster parent behaviors during child-led and parent-led play situations assessed using the DPICS were not found to significantly correlate with observed child emotion regulation during the clean-up situation assessed by the Global Dysregulation scale or the percentage of dysregulated intervals. The foster parent behaviors assessed included positive and negative talk, positive and negative touch, commands, and the percentage of opportunity for compliance commands. These analyses were exploratory in nature due to a lack of literature on parenting behaviors associated with child emotion regulation for foster parents and their foster children. Based on the literature on parent-child interactions between biological parents and their children, one would expect greater maternal warmth (e.g., positive talk and positive touch) and less maternal negative control (e.g., negative talk, negative touch, and commands) to be associated with greater emotion regulation (Gilliom, Shaw, Beck, Schonberg, \& Lukon, 2002; Calkins, Smith, Gill, \& Johnson, 1998). For the reasons stated previously, it is possible that the behavioral observations of child emotion regulation were not construct valid in the current study, which would explain a lack of relationship between foster parent behaviors and child emotion regulation measured observationally.

It is also possible that the emotion regulation abilities of the children in this study are unrelated to foster parent behaviors for other reasons. First, the amount of time each child resided with their foster parent at the time of the study is unknown to the investigators. It is possible that many of the children in the sample resided with their foster parent for too little time 
to expect foster parenting behavior to be related to child emotion regulation. Although inferences regarding causation cannot be made from a correlational study of this nature, one can assume that two variables are not causally related to each other if they are not related at all. In other words, it is possible that foster parent behaviors and child emotion regulation are not statistically related because they simply do not influence each other. Indeed, foster parent behaviors may not change the trajectory of emotion regulation abilities which are thought to first develop in infancy (Calkins, 1994). Additionally, child emotion regulation abilities may not influence the behavior of trained professional foster parents.

Of the foster parent behaviors assessed using the DPICS, only commands were found to significantly correlate with the ERC, with commands and ERC scores correlating moderately. The percentage of no opportunity commands was also found to moderately correlate with the ERC; this association was approaching statistical significance. Specifically, both commands and percentage of no opportunity commands were associated with poorer emotion regulation in this sample of foster children. This finding is not surprising given the association between negative maternal control and poor emotion regulation identified in the literature (Calkins, Smith, Gill, \& Johnson, 1998). It is possible that there is a bidirectional relationship between caregiver commands and child emotions regulation in that children who are less emotionally regulated may elicit more commands from their caregivers and a frequent caregiver commands may cause poorer emotion regulation in children. However, the directionality of the relationship between commands and child emotion regulation cannot be examined in a correlational study such as this.

\section{Association between Child Behavior Problems and Child Emotion Regulation}

Finally, child externalizing and internalizing behavior problems measured using the CBCL were not found to significantly correlate with observed child emotion regulation during 
the clean-up situation assessed by the Global Dysregulation scale or the percentage of dysregulated intervals. Again, it is possible that the observational measures of child emotion regulation are not valid for a number of reasons mentioned previously. There was a trend towards statistical significance found between child internalizing behavior problems and child emotion regulation assessed using the ERC in the current study. It is expected that this trend would become statistically significant with a larger sample size given the established relationship between child internalizing behavior problems and child emotion regulation identified in the literature (Kim-Spoon, Cicchetti, \& Rogosch, 2013). Surprisingly, child externalizing behavior problems were not found to correlate with the ERC. The relationship between child externalizing behavior problems and child emotion relation is well established in the literature (see Eisenberg, Spinrad, \& Eggum, 2010 for a review). As suggested previously, caregivers may have poor reliability when reporting on internal processes such as emotion regulation. Many studies that have found a relation between child externalizing behavior problems and child emotion regulation have utilized multiple methods to assess emotion regulation (Beauchaine, et al., 2013; Cole, Zahn-Waxler, Fox, Usher, \& Welch, 1996; Han \& Shaffer, 2013). It is possible that emotion regulation in an internal process that is difficult to assess using foster-parent report alone.

\section{Limitations and Future Directions}

Results from this study may have implications for future research in assessment of child emotion regulation with foster children. First, this study's findings suggest that the clean-up task of the DPICS may not elicit a strong enough negative emotional experience in children to allow for emotion regulation abilities to be observed. Thus, a direction for future research would be to observe child emotion regulation during task that is more likely to elicit a negative emotional 
response so that child emotion regulation can be observed. This may also be accomplished by conducting the assessment in a more ecologically valid environment than a novel space with novel toys as was used in this study. Another limitation of the current study was a lack of information regarding the length of time children were living with their foster parent. Collecting this information would allow researchers to account for the covariance between foster parent behaviors and child emotion regulation that could be attributed to the amount of time the child has resided with their current foster parent. Another limitation of this study was the skew of the positive and negative touch DPICS scores that violated the assumption of normality even after $\log$ transformation. The results for these parenting behaviors should be interpreted with caution for this study.

Although there were several limitations of the current study, it yielded interesting findings that could generate avenues for further research. First, foster-parent commands were found to correlate with foster-parent report of child emotion regulation; however, the directionality of this relation is currently unknown. A longitudinal study of foster-parent commands and foster child emotion regulation is necessary to better understand how these constructs are related. Second, foster child externalizing behavior problems were not found to correlate with foster child emotion regulation despite a consistent relation between these two constructs found in the literature. Further research is needed in order to examine the link between internalizing behavior problems and child emotion regulation and a lack of a relation between externalizing behavior problems and child emotion relation in foster child samples that likely have experienced maltreatment. Finally, although there was not a significant correlation between child emotion regulation assessed using the Global Dysregulation behavioral observation scale during the clean-up task of the DPICS and child emotion regulation assessed 
through caregiver-report, this finding suggests that future research might benefit from using other tasks to observe child emotion regulation that can supplement caregiver-report assessment of child emotion regulation. 


\section{References}

Abidin, R. (1983). Parenting Stress Index professional manual. Odessa, FL: Psychological Assessment Resources.

Abidin, R. R. (1990). The Parenting Stress Index Short Form. Charlottesville, VA: Pediatric Psychology Press.

Abidin, R. R. (1995). Manual for the Parenting Stress Index. Odessa, FL: Psychological Assessment Resources.

Achenbach, T. M., \& Edelbrock, C. S. (1983). Manual for the Child Behavior Checklist and Revised Child Behavior Profile, Burlington, VT: University of Vermont, Department of Psychiatry.

Achenbach, T.M., McConaughy, S.H., \& Howell C.T., (1987). Child/adolescent behavioral and emotional problems: Implications of cross-informant correlations for situational specificity. Psychological Bulletin, 101(4), 213-232.

Achenbach, T. M., \& Rescorla, L. (2001). Manual for the ASEBA school-age forms \& profiles. Burlington: University of Vermont, Research Center for Children, Youth, and Families.

Adrian, M., Zeman, J., \& Veits, G. (2011). Methodological implications of the affect revolution: A 35-year review of emotion regulation assessment in children. Journal Of Experimental Child Psychology, 110(2), 171-197. doi:10.1016/j.jecp.2011.03.009

Alink, L. A., Cicchetti, D., Kim, J., \& Rogosch, F. A. (2009). Mediating and moderating processes in the relation between maltreatment and psychopathology: Mother-child relationship quality and emotion regulation. Journal of Abnormal Child Psychology, 37(6), 831-843. doi:10.1007/s10802-009-9314-4 
Anthony, L. G., Anthony, B. J., Glanville, D. N., Naiman, D. Q., Waanders, C., \& Shaffer S. (2005). The relationships between parenting stress, parenting behaviour and preschoolers' social competence and behaviour problems in the classroom. Infant and Child Development, 14, 133-154.

Arnold, D. S., O'Leary, S. G., Wolff, L. S., \& Acker, M. M. (1993). The Parenting Scale: A measure of dysfunctional parenting in discipline situations. Psychological Assessment, 5, 137-144. doi:10.1037/1040-3590.5.2.137.

Bandura, A. (1977). Social learning theory. Englewood Cliffs, NJ: Prentice-Hall.

Beauchaine, T. P., Gatzke-Kopp, L., Neuhaus, E., Chipman, J., Reid, M., \& Webster-Stratton, C. (2013). Sympathetic- and parasympathetic-linked cardiac function and prediction of externalizing behavior, emotion regulation, and prosocial behavior among preschoolers treated for ADHD. Journal Of Consulting And Clinical Psychology, 81(3), 481-493. doi:10.1037/a0032302

Bradley, R. H., \& Caldwell, B. M. (1979). Home observation for measurement of the environment: A revision of the preschool scale. American Journal of Mental Deficiency, $84,235-244$.

Caldwell B \& Bradley R. (1984). Home Observation for Measurement of the Environment. Little Rock, AR: University of Arkansas at Little Rock.

Calkins, S. D. (1994). Origins and outcomes of individual differences in emotion regulation. Monographs of the Society for Research in Child Development, 59, 53-72.

Calkins, S. D., \& Dedmon, S. E. (2000). Physiological and behavioral regulation in two-year-old children with aggressive/destructive behavior problems. [Feature]. Journal of Abnormal Child Psychology, 28(2), 103-118. 
Calkins, S. D., \& Fox, N. A. (1992). The relations among infant temperament, security of attachment, and behavioral inhibition at twenty-four months. Child Development, 63(6), 1456-1472. doi:10.2307/1131568

Calkins, S. D., Smith, C. L., Gill, K. L., \& Johnson, M. C. (1998). Maternal interactive style across contexts: Relations to emotional, behavioral, and physiological regulation during toddlerhood. Social Development, 7(3), 350-369. doi:10.1111/1467-9507.00072

Cassidy J. (1994). Emotion regulation: Influences of attachment relationships. Monographs of the Society for Research in Child Development, 59, 228-83.

Chaffin, M., Silvosky, J.F., Funderburk, B., Valle, L.A., Brestan, E.V., Balachova, T., Jackson, S., Lensgraf, J., \& Bonner, B.L. (2004). Parent-child interaction therapy with physically abusive parents: Efficacy for reducing future abuse reports. Journal of Consulting and Clinical Psychology, 72, 500-510.

Chang, L., Schwartz, D., Dodge, K. A., \& McBride-Chang, C. (2003). Harsh Parenting in Relation to Child Emotion Regulation and Aggression. Journal Of Family Psychology, 17(4), 598-606. doi:10.1037/0893-3200.17.4.598

Chazan-Cohen, R., Raikes, H., Brooks-Gunn, J., Ayoub, C., Pan, B., Kisker, E. E., \& Fuligni, A. (2009). Low-income children's school readiness: Parent contributions over the first five years. Early Education And Development, 20(6), 958-977. doi:10.1080/10409280903362402

Cicchetti, D., Ganiban, J., \& Barnett, D. (1991). Contributions from the study of high-risk populations to understanding the development of emotion regulation. In J. Garber, K. A. Dodge (Eds.), The development of emotion regulation and dysregulation (pp. 15-48). New York, NY US: Cambridge University Press. doi:10.1017/CBO9780511663963.003 
Cole, P. M., Dennis, T. A., Smith-Simon, K. E., \& Cohen, L. H. (2009). Preschoolers' emotion regulation strategy understanding: Relations with emotion socialization and child selfregulation. Social Development, 18, 324-352. doi: 10.1111/j.1467-9507.2008.00503.x

Cole, P. M., Martin, S. E., \& Dennis, T. A. (2004). Emotion regulation as a scientific construct: Methodological challenges and directions for child development research. Child Development, $75,317-333$.

Cole, P.M., Zahn-Waxler, C., Fox, N., Usher, B. A. \& Welch, J. D. (1996). Individual differences and emotion regulation and behavior problems and preschool children. Journal of Abnormal Psychology, 105, (4), 518-529.

Colvin, A., Eyberg, S. M. \& Adams, C. D. (1999). Restandardization of the Eyberg Child Behavior Inventory. [On-line]. Available: http://pcit.phhp.ufl.edu. Last accessed: $1 / 08 / 2012$.

Cummings, E. M., \& Davies, P. (1996). Emotional security as a regulatory process in normal development and the development of psychopathology. Development \& Psychopathology, 8, 123-139.

Crnic, K. A., Gaze, C., \& Hoffman, C. (2005). Cumulative parenting stress across the preschool period: Relations to maternal parenting and child behaviour at age 5. Infant and Child Development, 14, 117-132.

Crnic, K. \& Greenberg, M. (1990). Minor parenting stress with young children. Child Development, 54, 209-217.

Davis, E. L., \& Levine, L. J. (2013). Emotion regulation strategies that promote learning: Reappraisal enhances children's memory for educational information. Child Development, 84(1), 361-374. doi:10.1111/j.1467-8624.2012.01836.x 
De Los Reyes, A., \& Kazdin, A. E. (2005). Informant Discrepancies in the Assessment of Childhood Psychopathology: A Critical Review, Theoretical Framework, and Recommendations for Further Study. Psychological Bulletin, 131(4), 483-509. doi:10.1037/0033-2909.131.4.483

Deater-Deckard, K. (1998). Parenting stress and child adjustment: Some old hypotheses and new questions. Clinical Psychology - Science and Practice, 5, 314-332.

Deater-Deckard, K., \& Scarr, S. (1996). Parenting stress among dual-earner mothers and fathers: Are there gender differences?. Journal of Family Psychology, 10(1), 45-59.

Denham, S. A., Mitchell-Copeland, J., Strandberg, K., Auerbach, S., \& Blair, K. (1997). Parental contributions to preschoolers' emotional competence: Direct and indirect effects. Motivation and Emotion, 21, 65-86.

Dodge, K. A. (1991). Emotion and social information processing. In J. Garber \& K.A. Dodge (Eds.), The development of emotion regulation and dysregulation (pp. 159-181). New York: Cambridge University Press.

Durbin, C. (2010). Validity of young children's self-reports of their emotion in response to structured laboratory tasks. Emotion, 10(4), 519-535. doi:10.1037/a0019008

Eisenberg, N., \& Fabes, R. A. (1992). Emotion, regulation, and the development of social competence. In M. S. Clark (Ed.), Review of personality and social psychology: Vol. 14. Emotion and social behavior (pp. 119-150). Newbury Park, CA: Sage.

Eisenberg, N., Hofer, C., \& Vaughan, J. (2007). Effortful Control and Its Socioemotional Consequences. In J. J. Gross (Ed.), Handbook of emotion regulation (pp. 287-306). New York, NY US: Guilford Press. 
Eisenberg, N., Spinrad, T. L., \& Eggum, N. D. (2010). Emotion-related self-regulation and its relation to children's maladjustment. Annual Review of Clinical Psychology, 6, 495-525.

Eyberg, S.M. (1988). Parent-child interaction therapy: Integration of traditional and behavioral concerns. Child and Family Behavior Therapy, 10, 33-46.

Eyberg, S.M., Nelson, M.M., Duke, M., \& Boggs, S.R. (2005). Manual for the dyadic-child interaction coding system $\left(3^{\text {rd }}\right.$ ed.).

Eyberg, S., \& Pincus, D. (1999). Eyberg Child Behavior Inventory \& Sutter-Eyberg Student Behavior Inventory-Revised: Professional Manual. Odessa, FL: Psychological Assessment Resources.

Eyberg, S.M. \& Robinson, E.A. (1983). Conduct problem behavior: Standardization of a behavioral rating scale with adolescents. Journal of Clinical Child Psychology, 12, 347357. doi:10.1207/s15374424jccp1203_19

Feng, X., Shaw, D. S., \& Moilanen, K. L. (2011). Parental negative control moderates the shyness-emotion regulation pathway to school-age internalizing symptoms. Journal Of Abnormal Child Psychology, 39(3), 425-436. doi:10.1007/s10802-010-9469-z

Feng, X., Shaw, D. S., \& Silk, J. S. (2008). Developmental trajectories of anxiety symptoms among boys across early and middle childhood. Journal of Abnormal Psychology, 117(1), $32-47$.

Frodi, A. M., \& Lamb, M. E. (1980). Child abusers' responses to infant smiles and cries. Child Development, 51(1), 238-241. doi:10.2307/1129612

Gable, S., \& Isabella, R. A. (1992). Maternal contributions to infant regulation of arousal. Infant Behavior and Development, 15, 95-107. 
Gilliom M., Shaw D. S., Beck J. E., Schonberg M. A., \& Lukon J. L. (2002). Anger regulation in disadvantaged preschool boys: strategies, antecedents, and the development of selfcontrol. Developmental Psychology, 38, 222-35.

Goldsmith, H. H., Reilly, J., Lemery, K. S., Longley, S., \& Prescott, A. (1995). The laboratory temperament assessment battery. Unpublished manual, University of Wisconsin, Madison, WI.

Graziano, P. A., Calkins, S. D., \& Keane, S. P. (2011). Sustained attention development during the toddlerhood to preschool period: Associations with toddlers' emotion regulation strategies and maternal behaviour. Infant and Child Development, 20(6), 389-408. doi:10.1002/icd.731

Graziano, P. A., Keane, S. P. \& Calkins, S. D. (2010). Maternal behaviour and children's early emotion regulation skills differentially predict development of children's reactive control and later effortful control. Infant and Child Development, 19, 333-353.

doi: 10.1002/icd.670

Gross, J.J. (1998). The emerging field of emotion regulation: An integrative review. Review of General Psychology, 2, 271-299.

Gross J. J. \& Thompson, R. A. (2007). Emotion regulation: conceptual foundations. In Gross, J. J. (Eds), Handbook of Emotion Regulation (pp. 3-24). New York: Guilford.

Gunnar, M., \& Quevedo, K. (2007). The Neurobiology of Stress and Development. Annual Review Of Psychology, 58, 145-173. doi:10.1146/annurev.psych.58.110405.085605

Han, Z., \& Shaffer, A. (2013). The relation of parental emotion dysregulation to children's psychopathology symptoms: The moderating role of child emotion dysregulation. Child Psychiatry And Human Development, 44(5), 591-601. doi:10.1007/s10578-012-0353-7 
Healey, C. V., \& Fisher, P. A. (2011). Young children in foster care and the development of favorable outcomes. Children And Youth Services Review, 33(10), 1822-1830. doi:10.1016/j.childyouth.2011.05.007

Hill, A. L., Degnan, K. A., Calkins, S. D., \& Keane, S. P. (2006). Profiles of externalizing behavior problems for boys and girls across preschool: The roles of emotion regulation and inattention. Developmental Psychology, 42(5), 913-928. doi:10.1037/00121649.42.5.913

Kagan, J., Reznick, J., \& Snidman, N. (1987). The physiology and psychology of behavioral inhibition in children. Child Development, 58(6), 1459-1473. doi:10.2307/1130685

Kim-Spoon, J., Cicchetti, D., \& Rogosch, F. A. (2013). A longitudinal study of emotion regulation, emotion lability-negativity, and internalizing symptomatology in maltreated and nonmaltreated children. Child Development, 84(2), 512-527. doi:10.1111/j.14678624.2012.01857.x

Kopp, C. B. (1989). Regulation of distress and negative emotions: A developmental view. Developmental Psychology, 25(3), 343-354. doi:10.1037/0012-1649.25.3.343

Li, W., Huichang, C., \& Xinyin, C. (2002). Predicting social functioning based on toddlers emotion regulation strategies. Acta Psychologica Sinica, 34(5), 500-504.

Maughan, A., \& Cicchetti, D. (2002). Impact of child maltreatment and interadult violence on children's emotion regulation abilities and socioemotional adjustment. Child Development, $73,1525-1542$

Maughan, A., Cicchetti, D., Toth, S. L., \& Rogosch, F. A. (2007). Early-occurring maternal depression and maternal negativity in predicting young children's emotion regulation and 
socioemotional difficulties. Journal Of Abnormal Child Psychology: An Official Publication Of The International Society For Research In Child And Adolescent.

McNeil, C. B. \& Hembree-Kigin, T. L. (2010). Parent-child interaction therapy. New York: Springer.

Morris, A., Robinson, L. R., \& Eisenberg, N. (2006). Applying a Multimethod Perspective to the Study of Developmental Psychology. In M. Eid, E. Diener, M. Eid, E. Diener (Eds.), Handbook of multimethod measurement in psychology (pp. 371-384). Washington, DC US: American Psychological Association. doi:10.1037/11383-025

Morris, A., Silk, J. S., Steinberg, L., Myers, S. S., \& Robinson, L. (2007). The role of the family context in the development of emotion regulation. Social Development, 16(2), 361-388. doi:10.1111/j.1467-9507.2007.00389.x

Parke, R. D. (1994). Progress, paradigms, and unresolved problems: A commentary on recent advances in our understanding of children's emotions. Merrill-Palmer Quarterly, 40, $157-169$.

Randazzo, K., Landsverk, J., \& Ganger, W. (2003). Three informants' reports of child behavior: Parents, teachers, and foster parents. Journal of The American Academy Of Child \& Adolescent Psychiatry, 42(11), 1343-1350. doi:10.1097/01.chi.0000085753.71002.da

Robinson, E. A., \& Eyberg, S. M. (1981). The Dyadic Parent-Child Interaction Coding System: Standardization and validation. Journal of Consulting and Clinical Psychology, 49, 245250.

Robinson, L. R., Morris, A., Heller, S., Scheeringa, M. S., Boris, N. W., \& Smyke, A. T. (2009). Relations between emotion regulation, parenting, and psychopathology in young 
maltreated children in out of home care. Journal Of Child And Family Studies, 18(4), 421-434. doi:10.1007/s10826-008-9246-6

Rodriguez, G., Graziano, P., Bagner, D., \& Hernandez, S. (2011). Utility of measuring emotion regulation in PCIT. Poster presented at the 2011 Biennial International Parent-Child Interaction Therapy Convention at Gainesville, FL.

Roggman, L. A., Moe, S. T., Hart, A. D., \& Forthun, L. F. (1994). Family leisure and social support: Relations with parenting stress and psychological well-being in Head Start parents. Early Childhood Research Quarterly, 9(3-4), 463-480. doi:10.1016/08852006(94)90020-5

Rohner, R. P. (1986). The warmth dimension: Foundations of parental acceptance-rejection. Thousand Oaks, CA: Sage.

Rydell, A., Berlin, L., \& Bohlin, G. (2003). Emotionality, emotion regulation, and adaptation among 5- to 8-year-old children. Emotion, 3(1), 30-47. doi:10.1037/1528-3542.3.1.30

Saudino, J. K., \& Plomin, R. (1997). Cognitive and temperamental mediators of genetic contributions to the home environment during infancy. Merrill-Palmer Quarterly, 43, 123.

Shields, A., \& Cicchetti, D. (1997). Emotion regulation among school-age children: the development and validation of a new criterion q-sort scale. Developmental Psychology, $33,906-916$.

Shields, A., \& Cicchetti, D. (1998). Reactive aggression among maltreated children: The contributions of attention and emotion dysregulation. Journal of Clinical Child Psychology, 27, 381-395. 
Shipman, K. L., Schneider, R., Fitzgerald, M. M., Sims, C., Swisher, L., \& Edwards, A. (2007). Maternal emotion socialization in maltreating and non-maltreating families: Implications for children's emotion regulation. Social Development, 16(2), 268-285. doi:10.1111/j.1467-9507.2007.00384.x

Stansbury, K., \& Zimmermann, L. K. (1999). Relations among child language skills, maternal socializations of emotion regulation, and child behavior problems. Child Psychiatry and Human Development, 30(2), 121-142. doi:10.1023/A:1021954402840

Suveg, C., Jacob, M. L., \& Payne, M. (2010). Parental interpersonal sensitivity and youth social problems: A mediational role for child emotion dysregulation. Journal Of Child And Family Studies, 19(6), 677-686. doi:10.1007/s10826-010-9354-y

Tarren-Sweeney, M. J., Hazell, P. L., \& Carr, V. J. (2004). Are foster parents reliable informants of children's behaviour problems?. Child: Care, Health And Development, 30(2), 167175. doi:10.1111/j.1365-2214.2003.00407.x

Teisl, M., \& Cicchetti, D. (2008). Physical abuse, cognitive and emotional processes, and aggressive/disruptive behavior problems. Social Development, 17(1), 1-23.

Thompson, R. A. (1994). Emotion regulation: A theme in search of definition. Monographs of the Society for Research in Child Development, 59(2-3 Serial No. 240), 25-52.

U.S. Department of Health and Human Services (2011). The AFCARS report: Preliminary FY 2010 estimates as of June 2011 Retrieved from http://www.acf.hhs.gov/programs/cb/stats _ research/afcars/tar/report18.htm

Webster-Stratton, C. (1985). Comparisons of behavior transactions between conduct- disordered children and their mothers in the clinic and at home. Journal of Abnormal Child Psychology, 13, 169-183. 
Webster-Stratton, C., \& Eyberg, S.M. (1982). Child temperament: Relationship with child behavior problems and parent-child interactions. Journal of Clinical Child Psychology, $11,123-129$.

Winslow, E. B., Shaw, D. S., Bruns, H., \& Kiebler, K. (1995). Parenting as a mediator of child behavior problems and maternal stress, support, and adjustment. Paper presented at the Biennial Meeting of the Society for Research in Child Development.

Yap, M. B. H., Allen, N. B., \& Sheeber, L. (2007). Using an emotion regulation framework to understand the role of temperament and family processes in risk for adolescent depressive disorders. Clinical Child and Family Psychology Review, 10(2), 180-196.

Teisl, M., \& Cicchetti, D. (2008). Physical abuse, cognitive and emotional processes, and aggressive/disruptive behavior problems. Social Development, 17(1), 1-23. 
Table 1

Means and Standard Deviations for Foster Child and Foster Parent Age

\begin{tabular}{lrr}
\hline Demographic Variable & \multicolumn{1}{c}{$M$} & \multicolumn{1}{c}{$S D$} \\
\hline Foster child age (in years) & 5.05 & 1.09 \\
Foster parent age (in years) & 46.57 & 11.75 \\
\hline
\end{tabular}

Table 2

Count of Foster Child and Foster Parent Gender and Race

\begin{tabular}{lcc}
\hline & Foster Child & Foster Parent \\
\hline Gender & 16 & \\
Male & 24 & 36 \\
Female & & \\
Race & 9 & 23 \\
Caucasian & 22 & 13 \\
African American & 2 & 0 \\
Hispanic & 1 & 0 \\
Asian & 6 & 4 \\
Mixed or "other" & & \\
\hline
\end{tabular}

Table 3

Means and Standard Deviations for Child Emotion Regulation Measures

\begin{tabular}{lrr}
\hline Emotion Regulation Measures & \multicolumn{1}{l}{$M$} & \multicolumn{1}{c}{$S D$} \\
\hline Emotion Regulation Checklist & 21.99 & 3.78 \\
Global Dysregulation & .75 & 1.08 \\
Percentage of dysregulated & 10.85 & 21.04 \\
intervals & & \\
\hline
\end{tabular}

Table 4

Correlations of Emotion Regulation Measures

\begin{tabular}{llll}
\hline & 1 & 2 & 3 \\
\hline 1. Emotion Regulation Checklist & - & & \\
2. Global Dysregulation & -.16 & - & \\
3. Percentage of dysregulated & -.17 & $.983 * *$ & - \\
$\quad$ intervals & & & \\
\hline$* \mathrm{p}<.05 . * * \mathrm{p}<.01$. & & &
\end{tabular}


Table 5

Means and Standard Deviations for Foster Parent Behavior Composites in CLP and PLP

\begin{tabular}{lrr}
\hline Foster Parent Behavior Composite & \multicolumn{1}{l}{$M$} & \multicolumn{1}{l}{$S D$} \\
\hline Positive verbal composite & 8.08 & 6.73 \\
Negative verbal composite & 4.05 & 3.34 \\
Positive touch composite & .53 & 1.38 \\
Negative touch composite & .10 & .38 \\
Command composite & 36.65 & 19.45 \\
Percentage of no opportunity & $50.67 \%$ & $20.12 \%$ \\
commands composite & & \\
\hline
\end{tabular}

Table 6

Pearson Correlations of Emotion Regulation Measures and Parenting Behaviors

\begin{tabular}{lccc}
\hline Foster Parent Behavior Composite & ERC & $\begin{array}{l}\text { Global } \\
\text { Dysregulation }\end{array}$ & $\begin{array}{l}\text { Percentage of } \\
\text { Dysregulated Intervals }\end{array}$ \\
\hline Positive verbal composite & .14 & .22 & .22 \\
Negative verbal composite & -.01 & -.20 & -.17 \\
Positive touch composite & .13 & -.04 & -.07 \\
Negative touch composite & .23 & .16 & .14 \\
Command composite & $.38^{*}$ & -.10 & -.12 \\
Percentage of no opportunity & .18 & -.21 & -.21 \\
commands composite & & & \\
\hline
\end{tabular}

$* \mathrm{p}<.05 . * * \mathrm{p}<.01$

Table 7

Means and Standard Deviations for Parent-Report of Child Behavior Problems

\begin{tabular}{lll}
\hline Child Behavior Checklist Scale & $M$ & $S D$ \\
\hline Internalizing behavior problems & 25.60 & 10.84 \\
Externalizing behavior problems & 31.95 & 14.86 \\
\hline
\end{tabular}

Table 8

Pearson Correlation of Emotion Regulation Measures and Child Behavior Problems

\begin{tabular}{llll}
\hline Child Behavior Checklist Scale & ERC & $\begin{array}{l}\text { Global } \\
\text { Dysregulation }\end{array}$ & $\begin{array}{l}\text { Percentage of } \\
\text { Dysregulated Intervals }\end{array}$ \\
\hline Internalizing behavior problems & -.31 & .08 & .09 \\
Externalizing behavior problems & -.09 & .14 & .17 \\
\hline
\end{tabular}

$* \mathrm{p}<.05 . * * \mathrm{p}<.01$. 
Graph 1

Count of Participants for Global Dysregulation Scores

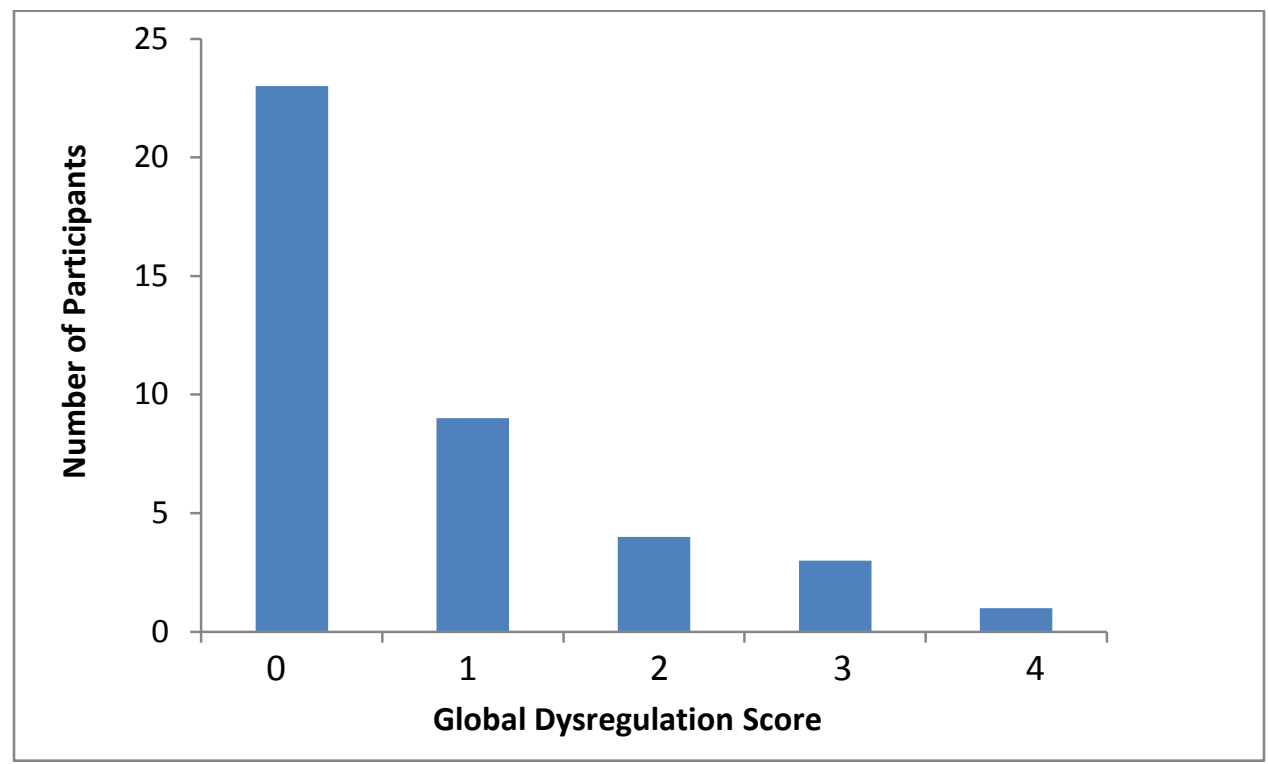

Note: A score of 0 indicates little to no dysregulation observed during clean-up task

Graph 2

Count of Participants for Percentage of Dysregulated Intervals Ranges

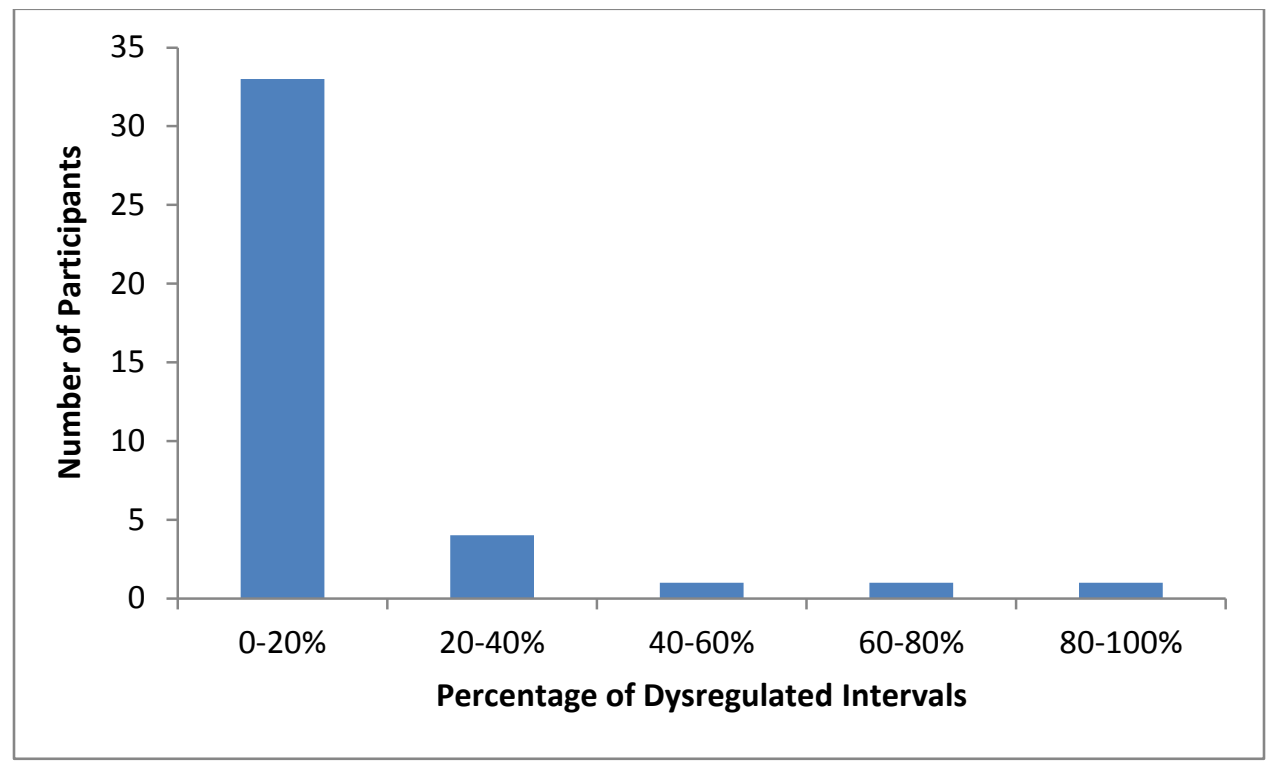

Note: A score of $0 \%$ indicates no dysregulation observed during clean-up task 